\title{
Slow progression to AIDS in intravenous drug users infected with HIV in Norway
}

Anne Eskild, Per Magnus, Christian Sohlberg, Peter Kittelsen, Johan H Olving, Brita Teige, Kari Skullerud

\begin{abstract}
Study objective - To study the rate of progression to AIDS and to death, and the causes of death among intravenous drug users in Norway.

Design - This was a prospective study. The study population was followed from diagnosis of HIV seropositivity until death or the end of the study period. The mean follow up was 56 months (range 173 months).

Setting - Subjects were recruited from a public HIV test clinic and followed by linkage to the National AIDS Registry and the National Cause of Death Registry. Participants - A total of 131 HIV positive intravenous drug users were included. The study population represented $75 \%$ of all intravenous drug users who had been diagnosed as HIV positive in Norway before 1987. None were lost to follow up.

Main results - Four years after study entry, $3 \%$ (95\% confidence interval, 0 , $6 \%$ ) had developed AIDS, while $15 \%$ (95\% CI, 9, 21\%) had died. Of the 25 subjects who died during the follow up period, 21 died from unnatural causes. Drug overdose accounted for 17 of these deaths. AIDS was the cause of death of three subjects only. Age more than 30 years at entry to the study was associated with short survival.

Conclusions - These results suggest that the progression rate to AIDS in intravenous drug users is slow.
\end{abstract}

( $($ Epidemiol Community Health 1994;48:383-387)

The number of deaths from infectious diseases not included in the definition of AIDS ${ }^{1-2}$ and from drug overdose have increased in populations of intravenous drug users since the introduction of HIV..$^{3-9}$ These observations suggest that the impact of the HIV epidemic on mortality cannot be measured in terms of the number of AIDS related deaths alone. Deaths not classified as being caused by AIDS, but associated with advanced HIV disease, suggest not only that additional causes of death may be attributed to advanced HIV infection, but also that the progression rate to AIDS among intravenous drug users ${ }^{10-14}$ may have been underestimated.

This study aimed to estimate the progression rate to AIDS and the progression rate to death after HIV diagnosis in a cohort of 131 HIV positive intravenous drug users followed for more than four years. By comparing these estimates and by scrutinising forensic reports on the causes of death, possible sources of bias in estimating the AIDS progression rate were investigated. In addition, gender, age, and the duration of intravenous drug use before the diagnosis of HIV positivity are studied as cofactors of survival.

\section{Methods}

\section{STUDY POPULATION}

All intravenous drug users $(n=131)$ with Norwegian residency who were registered as HIV positive before 1987 at the Department of AIDS Prevention, Oslo City Department of Health and Environment were included in a prospective study from the date of diagnosis of HIV seropositivity. The study sample represented $75 \%$ (131 of 174) of all intravenous drug users who had been diagnosed as HIV positive in Norway and thereby registered in the National HIV Registry ${ }^{15-16}$ before 1987. It is assumed that $80 \%$ of all intravenous drug users in Norway have been HIV tested. ${ }^{17}$

In this study an intravenous drug user is defined as someone who has ever injected drugs after 1979. Individual data on drug preferences were not available. Based upon other studies of intravenous drug users in the Oslo area, it is assumed that approximately $90 \%$ used mainly heroin, whereas $10 \%$ used mainly amphetamine. ${ }^{17}$ Methadone has not been used in the rehabilitation of intravenous drug users in Norway, except for a few cases. It is therefore believed that none, or very few, of this cohort received such treatment before or during the follow up period.

\section{DIAGNOSIS OF HIV SEROPOSITIVITY}

Almost all the subjects were HIV tested because of a self-experienced risk of being infected and after informed consent only. The serum analysis was performed at the Department of Microbiology, Ullevål Hospital, Oslo, with the ELISA technique and verified with the western blot method.

The exact time of seroconversion was unknown. It is believed, however, that the HIV epidemic among intravenous drug users in Norway did not begin until the second half of $1983 .{ }^{18}$ Thus, it is unlikely that HIV seroconversion had occurred more than three and a half years before study entry for any subject in the cohort.

Sixty seven of 131 subjects were diagnosed as HIV positive in 1985, and 64 in 1986. None were tested before 1985, since commercial kits for HIV antibody testing were not available. 
CLINICAL STATUS

One subject had AIDS when HIV positivity was diagnosed, but 115 were without major signs or symptoms of HIV infection at study entry and could therefore be classified as CDC II $(n=89)$ or CDC III $(n=26) \cdot{ }^{1-2}$ The remaining 15 had unknown clinical status. CD4 counts at study entry were not obtainable.

\section{FOLLOW UP}

Follow up means that each subject's identification data were linked to the National AIDS Registry, National Institute of Public Health, ${ }^{15}$ ${ }^{16}$ and the National Cause of Death Registry, Central Bureau of Statistics, ${ }^{19}$ at the end of the follow up period, January 1991. Information on vital status, AIDS status, date of AIDS diagnosis, and death were obtained from these registries. The actual linkage to the registries was performed in June 1991, when all cases of AIDS or deaths before 1 January 1991 were included. Consent to perform such linkage was obtained from the Norwegian Data Inspectorate.

The delay time in reported deaths is less than three months, and shorter in the AIDS registry as active surveillance has been built up with frequent contact from the registry to the few clinical departments in Norway that treat AIDS patients. Each subject was also linked to the Central Person Registry at the Central Bureau of Statistics. ${ }^{20}$ This registry includes all Norwegian residents. None were registered as emigrated at the end of the follow up period. Notification of emigration is compulsory by law.

Subjects who were not notified as having AIDS or as having died, were considered AIDS free and alive by the end of the follow up period. None were considered lost to follow up. Information on intravenous drug use or medical treatment during the follow up period were not obtainable.

\section{VARIABLES}

The information on age and the duration of intravenous drug use was obtained by a questionnaire at study entry. In the analysis, age was grouped as $<25$ years, 25-29 years, and $>29$ years. Duration of intravenous drug use before

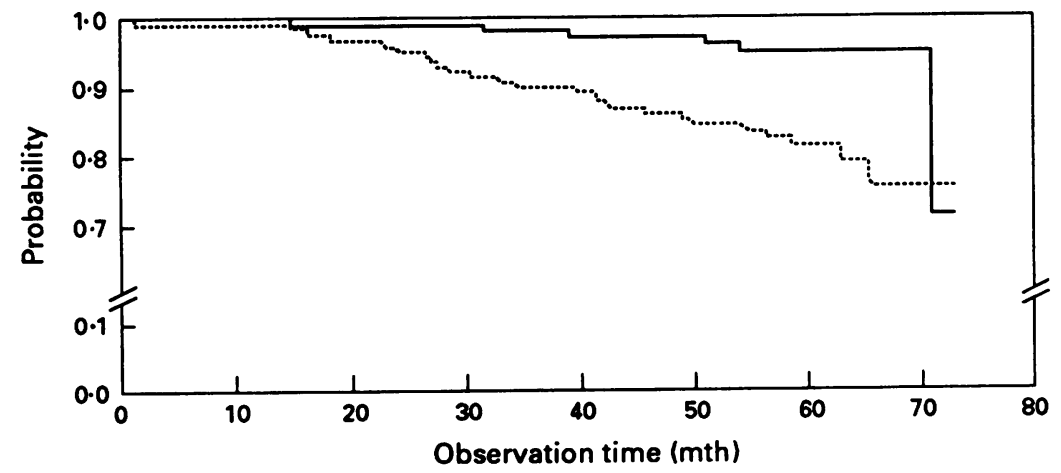

The probability of being AIDS free (upper curve) and the probability of survival (lower curve) calculated with the Kaplan-Meier estimator for $131 \mathrm{HIV}$ positive intravenous drug users.
HIV diagnosis was grouped as $<10$ years, 10 14 years, and $>14$ years.

\section{CAUSES OF DEATH}

The causes of death, according to the ICD-9 classification system were obtained from the National Death Registry. ${ }^{19}$ AIDS deaths were confirmed by the National AIDS Registry. ${ }^{15-16}$ Unnatural deaths were confirmed by forensic autopsy at the Institute of Forensic Medicine, University of Oslo. The forensic autopsy included routine inspection of all external and internal organs and histological examination of brain, lung, heart, and liver tissue. When organ pathology which could not be diagnosed by routine examination was suspected, additional examination was performed. The brains were also examined at the Division of Neuropathology, Rikshospitalet, Oslo. To study drug overdose as a possible cause of death, the post mortem blood concentration of morphine and codeine was routinely measured at the National Institute of Forensic Toxicology, University of Oslo. The autopsies were performed one to three days after death.

\section{STATISTICAL METHODS}

Survival and progression to AIDS were studied by applying the Kaplan-Meier estimator. ${ }^{21}$ The impact of gender, age, and duration of drug use on the rate of progression to death was studied by applying a Cox regression model, ${ }^{22}$ using the survival module in the program package SYSTAT. $^{23}$

\section{Results}

The mean follow up was 56 months (range 173 months). During the total follow up seven subjects $(5 \%)$ were diagnosed as having AIDS and 25 subjects $(19 \%)$ died. After one year, $1 \%(95 \%$ confidence interval (CI) $0,3 \%)$; after three years, $2 \%(0,4 \%)$; and after four years $3 \%(0,6 \%)$ were estimated to have developed AIDS.

One per cent $(0,3 \%)$ was estimated to have died after one year; $10 \%(5,15 \%)$ after three years; and $15 \%(9,21 \%)$ after four years. The probability of survival and the probability of being AIDS free according to the duration of observation are shown in the Figure.

Table 1 shows the main causes of death and findings at autopsy. Drug overdose was the main cause of death in 17 subjects, three of whom were suspected suicides. Twenty one died from unnatural causes (suicide, homicide, overdose). None of those who had died unnatural deaths had organ findings at autopsy compatible with the diagnosis of AIDS. AIDS was the cause of death for three subjects only. One subject who had been diagnosed with AIDS committed suicide. In 10 of the 19 brains examined by a neuropathologist, focal or diffuse inflammatory reactions with lymphocyte infiltration in the meninges, and/or microglial nodules in the brain were seen. None had HIV encephalopathy or leukoence- 
Table 1 Causes of death, organ findings, and drug concentrations at autopsy for the 25 subjects who died

\begin{tabular}{|c|c|c|c|c|c|}
\hline \multirow[b]{2}{*}{$\begin{array}{l}\text { Subject } \\
\text { no }\end{array}$} & \multirow[b]{2}{*}{ Main cause of death } & \multirow[b]{2}{*}{$\begin{array}{l}\text { Forensic } \\
\text { autopsy }\end{array}$} & \multirow[b]{2}{*}{ Organ finings at autopsy } & \multicolumn{2}{|c|}{ Post mortem drug concentrations } \\
\hline & & & & $\begin{array}{l}\text { Morphine } \\
(\mu \mathrm{mol} / \mathrm{l})\end{array}$ & $\begin{array}{l}\text { Codeine } \\
\text { ( } \mu \text { mol/ll) }\end{array}$ \\
\hline $\begin{array}{l}1-3 \\
4 \\
5 \\
6 \\
7 \\
8 \\
9 \\
10 \\
11 \\
12 \\
13 \\
14 \\
15 \\
16 \\
17 \\
18 \\
19 \\
20 \\
21 \\
22\end{array}$ & $\begin{array}{l}\text { AIDS } \\
\text { Liver failure } \\
\text { Bicycle accident } \\
\text { Homicide } \\
\text { Suicide (jumped from roof) } \\
\text { Suicide (overdose) } \\
\text { Suicide (overdose) } \\
\text { Suicide (overdose) } \\
\text { Suicide (drowned) } \\
\text { Drug overdose } \\
\text { Drug overdose } \\
\text { Drug overdose } \\
\text { Drug overdose } \\
\text { Drug overdose } \\
\text { Drug overdose } \\
\text { Drug overdose } \\
\text { Drug overdose } \\
\text { Drug overdose } \\
\text { Drug overdose } \\
\text { Drug overdose } \\
\text { Drug overdose } \\
\text { Drug overdose } \\
\text { Drug overdose }\end{array}$ & $\begin{array}{l}\text { No } \\
\text { No } \\
\text { No } \\
\text { Yes } \\
\text { No } \\
\text { Yes } \\
\text { Yes } \\
\text { Yes } \\
\text { Yes } \\
\text { Yes } \\
\text { Yes } \\
\text { Yes } \\
\text { Yes } \\
\text { Yes } \\
\text { Yes } \\
\text { Yes } \\
\text { Yes } \\
\text { Yes } \\
\text { Yes } \\
\text { Yes }\end{array}$ & $\begin{array}{l}\text { Meningitis } \\
\text { Diagnosed with AIDS } \\
\text { Vacular myelopathy } \\
\text { Myocarditis, hepatitis } \\
\text { Meningoencephalitis } \\
\text { No pathology } \\
\text { No pathology } \\
\text { No pathology } \\
\text { No pathology } \\
\text { Meningitis } \\
\text { Meningitis } \\
\text { Meningitis } \\
\text { Meningitis } \\
\text { Meningoencephalitis } \\
\text { Meningoencephalitis } \\
\text { Encephalitis } \\
\text { Meningoencephalitis, } \\
\text { Inflammation of heart and lungs } \\
\text { Inflammation of liver } \\
\text { Inflammation of liver } \\
\text { Inflammation of liver }\end{array}$ & $\begin{array}{l}20.0 \text { (methadone) } \\
7.0 \\
2.0 \\
0.7 \\
1.5 \\
0.9 \\
0 \cdot 8 \\
0.4 \\
0.9 \\
0 \\
0.5 \\
1.4 \\
1.4 \\
1.2\end{array}$ & $\begin{array}{l}0 \\
0 \\
1 \cdot 8 \\
0 \\
0 \\
0 \\
0 \\
1 \cdot 2 \\
0 \\
2 \cdot 3 \\
0 \\
0 \\
0 \cdot 2\end{array}$ \\
\hline
\end{tabular}

Table 2 Gender, age, and duration of intravenous drug use prior to study entry according to survival

\begin{tabular}{lrrr}
\hline & Dead & Alive & Total \\
\hline Gender: & 17 & 65 & 82 \\
$\quad$ Male & 8 & 41 & 49 \\
Female & & & \\
& & & \\
Age at study entry (y): & 7 & 37 & 44 \\
$\quad<25$ & 7 & 53 & 60 \\
$25-29$ & 11 & 16 & 27 \\
$>29$ & & & \\
No of years of intravenous & & \\
drug use prior to study entry: & 34 & 38 \\
$<10$ & 4 & 35 & 49 \\
$\quad 10-14$ & 7 & 37 & 44 \\
$>14$ & 25 & 106 & 131 \\
Total & 7 & & \\
\hline
\end{tabular}

Table 3 Relative risk of dying according to gender, age at study entry, and duration of intravenous drug use before study entry as estimated in a Cox regression model for 131 intravenous drug users

\begin{tabular}{|c|c|c|}
\hline & Relative risk & $\begin{array}{l}\text { (95\% confidence } \\
\text { interval) }\end{array}$ \\
\hline $\begin{array}{l}\text { Gender: } \\
\text { Male } \\
\text { Female }\end{array}$ & $\begin{array}{l}1 \cdot 3 \\
1 \cdot 0\end{array}$ & $(0 \cdot 6,3 \cdot 2)$ \\
\hline $\begin{array}{c}\text { Age at stud } \\
<25 \\
25-29 \\
>29\end{array}$ & $\begin{array}{l}0.3 \\
0.3 \\
1.0\end{array}$ & $\begin{array}{l}(0 \cdot 1,0.9) \\
(0.1,0.7)\end{array}$ \\
\hline $\begin{array}{l}\text { No of years } \\
\text { drug use pri } \\
<10 \\
10-14 \\
>14\end{array}$ & $\begin{array}{l}\text { nous } \\
\text { y entry: } \\
0.9 \\
2.4 \\
1.0\end{array}$ & $\begin{array}{l}(0.3,3.5) \\
(0.9,6.4)\end{array}$ \\
\hline
\end{tabular}

phalopathy which is characteristic of HIV infection. ${ }^{24}$

The distribution of gender, age, and duration of intravenous drug use before HIV diagnosis according to survival is shown in table 2 . Forty nine $(37 \%)$ were female. The mean age at the time of HIV diagnosis was 26 years (range 16-40). The mean duration of intravenous drug use before HIV diagnosis was 12.5 years (range $1-24$ ).

Gender was not associated with short survival, but being 30 years or more was (table 3 ). A duration of intravenous drug use of $10-14$ years before HIV diagnosis was associated with short survival, although not significantly so.

\section{Discussion}

In this study of HIV positive intravenous drug users, the rate of progression to death was estimated to be more rapid than the progression rate to AIDS. The main cause of death was drug overdose, and age more than 30 years at entry to the study was associated with a rapid progression to death.

It has been shown that morphine impairs lymphocyte reactivity and increases HIV replication. ${ }^{25-27}$ These findings suggest a more rapid progression to AIDS among intravenous drug users than in homosexual men. The existing estimates of the progression to AIDS among intravenous drug users, ${ }^{10-14}$ including the results from this study, are either equal to or slower than the estimates for homosexual men. ${ }^{28-29}$ Four years after seroconversion, $13 \%$ $(95 \%$ CI $7,19 \%)$ of the homosexual men in the San Francisco hepatitis B vaccine trials were estimated to have developed AIDS. ${ }^{28}$ That finding agrees with the estimates of the progression rate to AIDS among homosexual men whose time of seroconversion was known in the MACS study. ${ }^{29}$ In an Italian study of intravenous drug users, $17 \cdot 8 \%$ were estimated to have AIDS after four years from seroconversion. ${ }^{11}$ In the later study, however, the mean follow up period was only 26 months.

In our study of intravenous drug users, however, only $3 \%(0,6 \%)$ were estimated to have developed AIDS after four years. HIV seroconversion had occurred before study entry, and probably within three and a half years before enrolment. ${ }^{18}$ Thus, the progression to AIDS after HIV diagnosis, as estimated in this study, represents a maximum estimate of the true progression rate to AIDS after HIV seroconversion. Age has been shown to be a cofactor of progression to AIDS. ${ }^{12}$ The mean age in the men with a known time of 
seroconversion in the San Francisco hepatitis $B$ vaccine trials was 30 years. In this study, the mean age was 26 years. It is unlikely that this difference in age can explain the difference in progression to AIDS.

Potential sources of bias in estimating the progression rate to AIDS have not been discussed a great deal in the published reports. Based on the design and the results of this study, the most important sources of bias selection bias in recruitment and in censoring, and underdiagnosis of AIDS - will be discussed.

Selection of subjects with slow HIV disease progression is unlikely to represent a major source of bias in this study, since most subjects are assumed to have been HIV infected less than two years before study entry. During the first two years after seroconversion very few are expected to develop AIDS. Before 1987 only two intravenous drug users had been diagnosed with AIDS in Norway. ${ }^{15-16}$

Selection bias in censoring might have occurred if HIV infection had been the underlying cause of death in those who died from causes unrelated to AIDS. A key concept in survival analysis, which is used for estimating the AIDS progression rate, is censoring. The subjects who die before developing AIDS, are considered as censored. In the analysis they are used as a part of the study population until censoring. An underlying assumption in the estimation of the progression rate to AIDS is that subjects who are censored have the same progression as the subjects who are not censored. Since unnatural death was the major cause of censoring in this study it could be postulated that such deaths may be attributed to HIV infection. The inflammatory reactions of the brain tissue, which were compatible with viral infection, may be associated with HIV disease. These findings have been seen more frequently in HIV positive than HIV negative intravenous drug users post mortem, ${ }^{30}$ and have been associated with early brain changes in HIV infection. ${ }^{31}$ The post mortem blood drug concentrations in all overdose deaths, however, were considered lethal. It is therefore uncertain whether the brain inflammation contributed to death. In an earlier study, higher post mortem drug concentrations were seen in HIV positive than HIV negative subjects who had died from drug overdose $(1.05 \mu \mathrm{mol} / 1$ versus $0.77 \mu \mathrm{mol} / 1){ }^{30}$ The tolerance to drugs and the prevalence of brain pathology in HIV positive intravenous drug users who remain alive is not known. Thus, an association between unnatural deaths and HIV disease progression cannot be ruled out. AIDS, however, could not be diagnosed in any subject on the basis of autopsy findings.

Underdiagnosis of AIDS may have occurred in subjects who were alive at the end of the follow up. However, several health care workers and social workers were available to HIV positive intravenous drug users in health institutions, detoxification clinics, prisons, and in the streets of Oslo where these people usually gather. Thus, it is unlikely that a significant number have remained undiagnosed for a long period of time. The fact that none of those who died from unnatural causes and underwent autopsy had findings compatible with AIDS, supports this.

The reporting delay to the National AIDS Registry has been minimal. There are only five hospitals in Norway that treat AIDS patients. The communication between these hospitals and the National AIDS Registry has been on a regular monthly basis. At the end of the study period there was a total of 195 AIDS cases diagnosed in Norway, 16 of whom were intravenous drug users. Since there have been relatively few AIDS cases and few hospitals involved in the treatment, it is unlikely that diagnosed cases would remain unnotified for a long time.

Unnotified AIDS cases might, however, have occurred if several subjects in the study population had developed AIDS while living abroad and had not returned to Norway. This is unlikely since medical care is free and the welfare system is well developed for intravenous drug users in Norway.

The proportion estimated as dead in this study equals the proportion estimated with AIDS in studies of homosexual men. ${ }^{28-29}$ As discussed above, it is unlikely that a significant number of deaths in this study could be attributed to AIDS. It must also be kept in mind that the follow up period in this study starts with the date of HIV diagnosis and not with the date of seroconversion. Hence, the proportion estimated with AIDS or as dead represents a maximum estimate.

Despite different sources of bias that may have caused an underestimate of the progression rate to AIDS, the main finding in this study suggests a slow progression to AIDS among HIV infected intravenous drug users in Norway. Observed differences in the progression rate to AIDS between groups should encourage further studies of cofactors of HIV disease progression.

We are grateful to clinicians in Norway who have diligently reported all AIDS cases. We are also grateful to the employees of the National AIDS and the National Death Registries who have helped us in data collection and to the employees at the have helped us in data collection and to the employees at the National Institute of Forensic Toxicology for the analysis of post mortem drug concentrations. This study was supported by the Norwegian Research Council for Science and the Hu
ies and approved by the Norwegian Data Inspectorate.

1 Centers for disease control: Acquired Immunodeficiency syndrome (AIDS) - United States. MMWR 1982;31: 507-14.

2 Centers for disease control: Revision of the CDC surveillance case definition of the acquired immunodeficiency syndrome. $M M W R$ 1987;36:3-15.

3 Kholoud P, McCormick A, Tillett HE. Death in HIV infected persons without AIDS. Proceedings of the VIIth International Conference on AIDS, 1991 (WC 3064).

4 Selwyn PA, Feingold AR, Hartel D, et al. Increased risk of bacterial pneumonia in HIV-infected intravenous drug users without AIDS. AIDS 1988;2:267-72.

5 Selwyn PA, Hartel D, Wasserman W, Drucker E. Impact of the AIDS epidemic on morbidity and mortality among intravenous drug users in a New York City methadone intravenous drug users in a New York City methadone 62 .

6 Stoneburner RL, Des Jarlais DC, Benezra D, et al. A larger spectrum of severe HIV-1-related disease in intravenous drug users in New York city. Science 1988;242:916-19.

7 Buehler JW, Devine OJ, Berkelman RL, Chevarley FM. Impact of the human immunodeficiency virus epidemic on Impact of the human immunodeficiency virus epidemic on
mortality trends in young men, United States. Am $\mathcal{F}$ Public mortality trends in young

8 McCormick A. Trends in mortality statistics in England and Wales with particular reference to AIDS from 1984 to Wales with particular reference to

9 McCormick A. Excess mortality associated with the HIV epidemic in England and Wales. BMF 1991;302:1375-6. 
10 Des Jarlais DC, Friedman SR, Marmor M, et al. Development of AIDS, HIV seroconversion, and potential cofactors for T4 cell loss in a cohort of intravenous drug users. AIDS 1987;1:105-11.

11 Rezza G, Lazzarin A, Angarano G, et al. The natural history of HIV infection in intravenous drug users: risk of disease progression in a cohort of seroconverters. AIDS 1989;3:87-90.

12 Mariotto A, Mariotti S, Pezzotti P, Rezza G, Verdecchia A. Effects of age and transmission group on the AIDS incubation period. Proceedings of the VIIth International Conference on AIDS, 1991 (MC 3130).

13 Margolick J, Munoz A, Vlahov D, et al. Changes in Tlymphocyte subsets in intravenous drug users with HIV-1 infection. FAMA 1992;267:1631-6.

14 Fernandez-Cruz E, Desco $M$, Montes MG, Longo N, Gonzalez B, Zabay JM. Immunological and serological markers predictive of progression to AIDS in a cohort of HIV-infected drug users. AIDS 1990;4:987-94.

15 National Institute of Public Health, Norway. AIDS prevention in Norway. Oslo: National Institute of Public Health $1989 ; 22-4$.

16 Directorate of Health. Notification of HTLV III/LAV infection (In Norwegian). Oslo: The Directorate of Health, 1986

17 Skretting A, Skog O-J. Arrested IVDUs (In Norwegian). SIFA report $1 / 89$. Oslo: National Institute for Alcohol SIFA report $1 / 89$. Oslo:

18 Dobloug JH, Bruun JN, Skaug K, The early introduction of HIV infection among Norwegians at highest risk. Scand F Infect Dis 1990;22:753-4.

19 Central Bureau of Statistics, Norway. Causes of death (health statistics). Oslo: Central Bureau of Statistics, 1990.

20 Central Bureau of Statistics, Norway. Statistical yearbook. Oslo: Central Bureau of Statistics, 1990.
21 Kaplan EL, Meier P. Nonparametric estimation from incomplete observations. F Am Statist Assoc 1958;53:457-81.

22 Cox DR, Oaks D. Analysis of survival data. New York: Chapman and Hall, 1984.

23 Steinberg D, Colla P. Survival: A supplementary module for SYSTAT. Evanston, IL: SYSTAT Inc. 1988.

24 Budka H, Wiley CA, Kleihues P, et al. HIV associated disease of the nervous system: Review of nomenclature and proposal for neuropathology-based terminology. Brain Pathology 1991;1:143-52.

25 Mientjes GH, Meidema F, Ameijden EJ, Hoek AA, Schellekens PT, Roos MT, Coutinho RA. Frequent injecting impairs lymphocyte reactivity in HIV positive and HIV negative drug users. AIDS 1991;5:35-41.

26 Arora PK, Fride E, Petitto J, Waggie K, Skolnick P Morphine-induced immune alterations in vivo. Cell Immunol 1990;126:343-53.

27 Peterson PK, Sharp BM, Gekker G, Portoghese PS, Sannerud K, Balfour HH. Morphine promotes the growth of HIV-1 in human peripheral blood mononuclear cell cocultures. AIDS 1990;4:869-73.

28 Hessol NA, Lifson AR, O'Malley PM, Doll L S, Jaffe HW, Rutherford GW. Prevalence, incidence and progression of human immunodeficiency virus in homosexual men in hepatitis B vaccine trials. Am f Epidemiol 1989;130:1167-75.

29 Munoz A, Wang MC, Bass S, Taylor JM, Kingsley, Lahmiel JS, Polk BF. Acquired immunodeficiency syndrome (AIDS) - free time after human immunodeficiency virus type 1 (HIV-1) seroconversion in homosexual men. $A m \mathcal{F}$ Epidemiol 1989;130:530-9.

30 Filseth OM, Fossen K, Halvorsen V, et al. Opioid related deaths among drug abusers (In Norwegian). $\mathcal{F}$ Norwegian Med Assoc 1991;111:1629-32.

31 Gray F, Lescs M-C, Keohane C, et al. Early brain changes in HIV infection: Neuropathological study of $11 \mathrm{HIV}$ seropositive, non-AIDS cases. 7 Neuropathol Exp Neurol 1992;51:177-85. 